\title{
Relation between chemical composition, morphology, and microstructure of poly(ether ether ketone)/reduced graphene oxide nanocomposite coatings obtained by electrophoretic deposition
}

\author{
Eduin I. González-Castillo ${ }^{1,2, *}$ (1), Michal Žitňan ${ }^{2}$, Yadir Torres ${ }^{3}$, Peter S. Shuttleworth ${ }^{4}$, \\ Dušan Galusek ${ }^{2}$, Gary Ellis ${ }^{4}$, and Aldo R. Boccaccini ${ }^{1, *}$ \\ ${ }^{7}$ Institute of Biomaterials, University of Erlangen-Nuremberg, Cauerstrasse 6, 91058 Erlangen, Germany \\ ${ }^{2}$ Centre for Functional and Surface Functionalized Glass, Študentská 2, 91150 Trenčín, Slovakia \\ ${ }^{3}$ Materials and Transport Science and Engineering, Sevilla University, Virgen de África 7, 41011 Sevilla, Spain \\ ${ }^{4}$ Institute of Polymer Science and Technology (ICTP-CSIC), Juan de la Cierva 3, 28006 Madrid, Spain
}

Received: 28 December 2021

Accepted: 7 February 2022

Published online:

2 March 2022

(C) The Author(s) 2022

\begin{abstract}
The effect of the chemical composition on the morphology and microstructure of poly(ether ether ketone) (PEEK)/reduced graphene oxide (RGO) nanocomposite coatings is analyzed. RGO induced three main morphological features in the nanocomposites: (i) a large-scale co-continuous morphology related to nanosheets whose basal planes were mainly aligned with the coating surface, (ii) a dendritic morphology of PEEK domains, and (iii) irregular domains related to the deposition of PEEK particles wrapped by the nanosheets. The development of these morphological features was influenced by the RGO content, allowing the modification of the surface roughness. RGO also induced changes in the melting and non-isothermal crystallization of the polymeric matrix and promoted transcrystallinity in PEEK that, in turn, was a key factor in the development of the final microstructure. In addition, polymer chain mobility was observed to be hindered at high nanofiller concentrations, increasing the glass transition temperature, and diminishing the recrystallization of the polymeric matrix.
\end{abstract}

\section{Introduction}

Poly(ether ether ketone) (PEEK) is a semicrystalline thermoplastic and polyaromatic linear polymer that combines outstanding mechanical properties with high-temperature stability, and low smoke emission and flammability [1-5]. Due to these properties, PEEK is a high-performance polymer with applications in diverse areas, ranging from medicine to aerospace [5]. When used as coating, PEEK has good

Handling Editor: Catalin Croitoru.

Address correspondence to E-mail: eduin.gonzalez@tnuni.sk; aldo.boccaccini@ww.uni-erlangen.de 
adhesion to metallic substrates. Moreover, the properties of PEEK-based coatings can be tailored to meet specific technological requirements by incorporating carbonaceous, ceramic, and metallic fillers whose dimensions are in the nano- or micro-scale [6]. In the field of advanced composites and nanocomposites coatings, the electrophoretic deposition (EPD) process has received increasing attention in recent years because it offers a good control of mass and thickness of the deposits whilst favoring the development of specific morphologies [7-9]. In our previous work, interesting morphological features were observed in PEEK/reduced graphene oxide (RGO) nanocomposite coatings obtained by electrophoretic co-deposition of PEEK and graphene oxide (GO) particles followed by a thermal treatment [10]. The electric field applied during EPD promoted the basal plane alignment of the GO nanosheets with the coating surface, meanwhile the thermal treatment and GO content induced a dendritic morphology of PEEK domains. Furthermore, the increase of GO nanosheet content was associated with the development of irregular domains related to the deposition of PEEK particles wrapped by GO nanosheets [10]. Incorporation of a small amount of reduced graphene oxide (RGO) into polymeric matrices can significantly improve mechanical and functional properties of the nanocomposites [11]. RGO is obtained by removing large amounts of oxygen-containing groups from GO by chemical, thermal, or other methods. Hence, RGO is a two-dimensional (2D) monolayer material made of crystalline domains that comprise $\mathrm{sp}^{2}$ carbon atoms disposed of in a hexagonal or honeycomb lattice, and amorphous domains that result from the distortions provoked by residual $\mathrm{sp}^{3} \mathrm{C}-\mathrm{O}$ bonds [12-15]. The aforementioned intrinsic structure endows RGO with exceptional properties, for instance, flexibility, high Young's modulus, and strength, high specific surface area, and excellent thermal, and electrical conductivity [13].

As is the case for other semicrystalline polymers, the properties of PEEK are heavily dependent on its crystallinity [16, 17]. In this respect, nano- and microfillers could affect the melting and crystallization processes of PEEK [18, 19], for instance, heterogenous nucleation promoted by existing surfaces could induce transcrystallinity in PEEK during its crystallization from the melt [20-24]. In this respect, carbon fibers have been shown to affect the nucleation and crystal growth rate in PEEK matrices, modifying not only the microstructure characteristics as a result of transcrystallinity (e.g., crystallinity degree and crystal orientation) but also the mechanical properties of the PEEK matrix [24]. Moreover, it has been reported that RGO can provoke variations in the nucleation, growth, and crystal orientation in semicrystalline polymers [25, 26], nonetheless, to the authors' knowledge, the effect of RGO on the crystallization of PEEK has not been investigated to date. The effect of nano- and micro-fillers on crystallinity and other properties of polymer-based composites is strongly dependent on factors such as matrix-filler interaction, nanoparticle dispersion, nanoparticle size and shape, and alignment as in the case of nanosheets [27, 28]. Thus, the properties of PEEK/RGO nanocomposite coatings could be largely influenced by the preferential basal-plane alignment and the wrapping effect of the nanosheets, and a profound understanding of the microstructure-property correlation is required for optimising the desired properties of PEEK/RGO nanocomposite coatings.

In this work, the correlation between the morphology and crystalline structure of PEEK interacting with RGO nanosheets in electrophoretically obtained PEEK/RGO nanocomposites is meticulously analysed by varying the nanofiller content. Scanning electron microscopy, atomic force microscopy, confocal laser scanning microscopy, simultaneous thermal analysis, and grazing incidence $X$-ray diffraction were employed to characterise the prepared nanocomposites. To the authors' knowledge this is the first study comprehensively characterising the interaction of RGO and PEEK in relation to PEEK crystallisation.

\section{Experimental}

\section{Materials}

PEEK powder VICTREX ${ }^{\mathrm{TM}}$ PEEK VICOTE ${ }^{\mathrm{TM}} 704$ (Victrex PCL, UK) for coating of ferrous and nonferrous metals were used as the polymer matrix and its properties are summarised in Table $1[29,30]$. Single-layer graphene oxide dispersed in deionized water (flake size $0.5-2.0 \mu \mathrm{m}$, thickness $0.6-1.2 \mathrm{~nm}$, single-layer ratio $>80 \%$, and concentration of $10 \mathrm{mg}$ $\mathrm{mL}^{-1}$ ) commercialised under the trademark of GNO1W001 (ACS Materials, USA) was used as the nanofiller. Ethanol denatured with about $1 \%$ methyl 
Table 1 Properties of VICTREX ${ }^{\mathrm{TM}}$ PEEK VICOTE $^{\mathrm{TM}} 704[29,30]$

\begin{tabular}{llll} 
Property & & & \\
\hline Density $\left(\mathrm{kg} \mathrm{m}^{-3}\right)$ & Melting temperature $\left({ }^{\circ} \mathrm{C}\right)$ & Glass transition $\left({ }^{\circ} \mathrm{C}\right)$ & Average particle size $(\mu \mathrm{m})$ \\
\hline 1.32 & 343 & 143 & 10 \\
\hline
\end{tabular}

Table 2 Properties and chemical composition of stainless steel $316 \mathrm{~L}$. All the property values correspond to a temperature of $20{ }^{\circ} \mathrm{C}$ [31]

\begin{tabular}{ll}
\hline Property & Value \\
\hline Density $\left(\mathrm{kg} \mathrm{m}^{-3}\right)$ & 8.0 \\
Thermal conductivity $\left(\mathrm{W} \mathrm{m}^{-1} \mathrm{~K}^{-1}\right)$ & 15 \\
Elastic modulus $(\mathrm{GPa})$ & 200 \\
Specific thermal capacity $\left(\mathrm{J} \mathrm{kg}^{-1} \mathrm{~K}^{-1}\right)$ & 500 \\
Electrical resistivity $\left(\Omega \mathrm{mm}^{2} \mathrm{~m}^{-1}\right)$ & 0.75 \\
Linear thermal expansion coefficient $\left(10^{-6} \mathrm{~K}^{-1}\right)$ & 16.0 \\
Yield strength $(\mathrm{MPa})$ & 220 \\
Tensile strength $(\mathrm{MPa})$ & $520-670$ \\
Chemical composition (heat analysis in wt.\%) & $\mathrm{C} 0.03 / \mathrm{Si} 1.00 / \mathrm{Mn} 2.00 / \mathrm{P} 0.05 / \mathrm{S} 0.015 / \mathrm{Cr}$ \\
& $16.50-18.50 / \mathrm{Ni} 10.0-13.00 / \mathrm{N} 0.10 / \mathrm{Mo} 2.00-2.50 / \mathrm{Fe}$ balance
\end{tabular}

ethyl ketone for analysis (EMSURE®, Germany), and isopropanol 99.9\% purity (Sigma-Aldrich, Germany) were utilised as the suspension medium for EPD process. Stainless steel $316 \mathrm{~L}$ foil with dimensions of $15 \mathrm{~mm}$ (width) $\times 0.2 \mathrm{~mm}$ (thickness) (Thyssenkrupp, Germany) was used for preparing the counter electrodes. The physical and chemical properties and chemical composition of stainless steel $316 \mathrm{~L}$ foil are listed in Table 2 [31]. VICTREX ${ }^{\mathrm{TM}}$ PEEK VICOTE ${ }^{\mathrm{TM}}$ 704, graphene oxide GNO1W001, and stainless steel $316 \mathrm{~L}$ foil are hereafter referred as PEEK, GO, and stainless steel, respectively.

\section{Preparation of the PEEK/RGO nanocomposite coatings}

PEEK/RGO nanocomposite coatings were developed by electrophoretic co-deposition of PEEK particles and graphene oxide (GO) nanosheets, followed by thermal treatment. The preparation has been described in detail in our previous work [10] and is summarised in Fig. 1. Briefly, PEEK powder $(3 \mathrm{wt} \%)$ was added into the non-aqueous media ( $40 \mathrm{~mL}$ of ethanol $95 \mathrm{vol} \%$ and 2-propanol $5 \mathrm{vol} \%$ ), and ultrasonicated for an effective time of 6 min (active interval of $0.5 \mathrm{~s}$, followed by an inactive one of $2.1 \mathrm{~s}$ ) at constant amplitude value of $30 \%$, Fig. 1a. Compositions of 0.5 , 1.0 and $3.0 \mathrm{GO}$ wt. \% relative to the PEEK mass were prepared by adding $0.5,1.0$, and $3.0 \mathrm{~mL}$ of GO suspension (concentration of $10 \mathrm{mg} \mathrm{mL} \mathrm{m}^{-1}$ ) to the previously ultrasonicated PEEK suspensions, Fig. $1 \mathrm{~b}$. Table 3 lists the nomenclature and characteristics of the suspensions prepared.

Stainless steel electrode plates (dimensions: $30 \mathrm{~mm} \times 15 \mathrm{~mm} \times 0.2 \mathrm{~mm}$ ) were polished with a P600 CarbiMetTM grinding paper (Buhler Group, Switzerland) and subsequently cleaned for $30 \mathrm{~min}$ in ethanol using an ultrasonic bath. Prior to the EPD process, the suspensions were magnetically stirred for $24 \mathrm{~h}$ at $250 \mathrm{rpm}$ and at room temperature. Two polished-and-cleaned stainless-steel electrodes were immersed into the suspension in a parallel plate arrangement. Based on our previous work, a constant voltage of $30 \mathrm{~V}$, deposition time of $3 \mathrm{~min}$, and $10 \mathrm{~mm}$ distance between electrodes were selected, as these EPD experimental conditions led to the uniform coatings, Fig. 1c. Once the EPD process was completed, the coated electrode plates were carefully extracted from the suspension to prevent damage to the deposited layer.

Prior to thermal treatment, the samples obtained by using EPD were dried in air at $150{ }^{\circ} \mathrm{C}$ for $3 \mathrm{~h}$. The thermal treatment process, also in the ambient atmosphere, allowed densification of the coating and erased any thermal history effects of the polymeric matrix, as well as reducing the GO. The thermal treatment consisted of the following thermal cycles: (i) heating from ambient temperature to $380{ }^{\circ} \mathrm{C}$ at a rate of $10{ }^{\circ} \mathrm{C} \mathrm{min}{ }^{-1}$, (ii) isothermal dwell at $380{ }^{\circ} \mathrm{C}$ for 


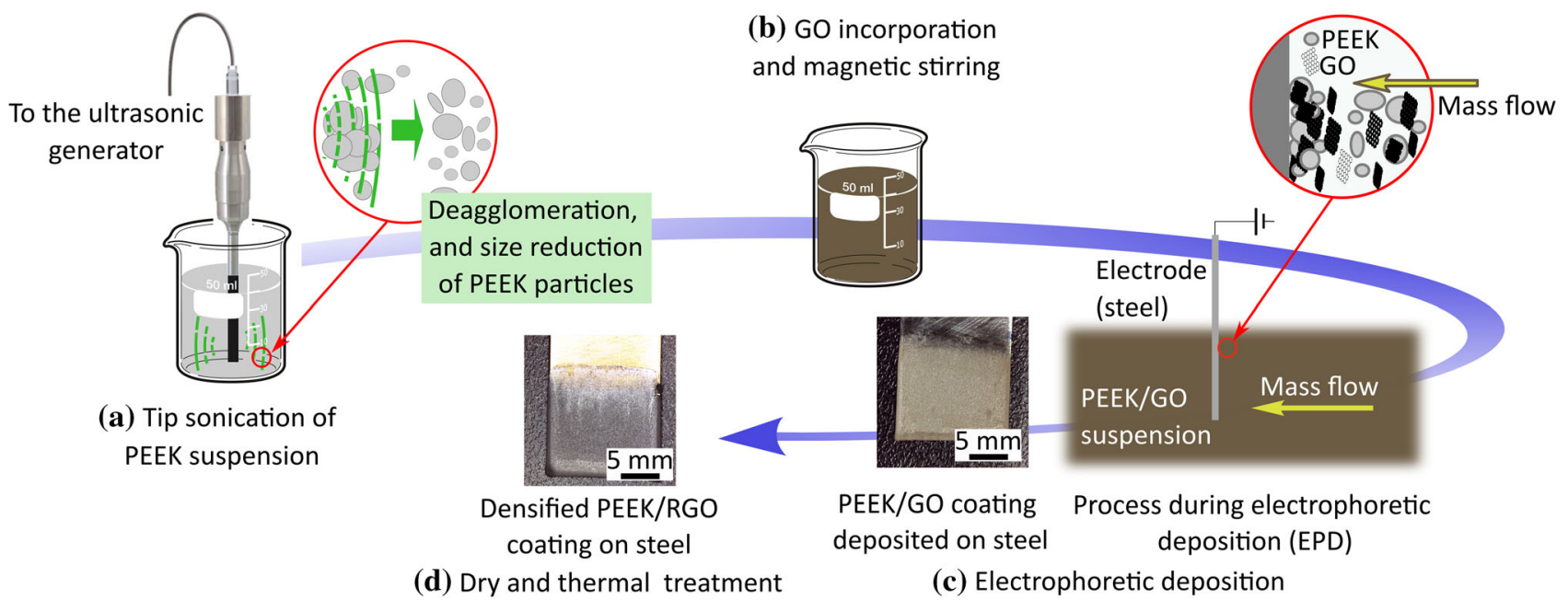

Figure 1 Scheme of the methodology implemented in the preparation of the PEEK/RGO nanocomposite coatings involving EPD.

Table 3 Nomenclature and characteristics of the suspensions prepared

\begin{tabular}{|c|c|c|c|c|}
\hline \multicolumn{4}{|l|}{ Suspension } & \multirow{3}{*}{$\begin{array}{l}\text { Nomenclature used for the thermally } \\
\text { treated coatings }\end{array}$} \\
\hline \multirow[t]{2}{*}{ Nomenclature } & \multicolumn{3}{|l|}{ Content } & \\
\hline & $\begin{array}{l}\text { GO suspension to ethanol/ } \\
\text { isopropanol (vol. \%) }\end{array}$ & $\begin{array}{l}\text { GO to PEEK } \\
\text { (wt. } \% \text { ) }\end{array}$ & $\begin{array}{l}\text { Total solid } \\
\text { content }(\%)\end{array}$ & \\
\hline PEEK & 0 & 0 & 3.00 & PEEK-C \\
\hline PEEK/0.5GO & 1.25 & 0.5 & 3.01 & $\mathrm{NC}-1$ \\
\hline PEEK/1.0GO & 2.50 & 1.0 & 3.03 & $\mathrm{NC}-2$ \\
\hline $\mathrm{PEEK} / 3.0 \mathrm{GO}$ & 7.50 & 3.0 & 3.09 & $\mathrm{NC}-3$ \\
\hline
\end{tabular}

Regarding the PEEK-based coatings, the nomenclature corresponds to the materials after the thermal treatment. In all cases, the mass fraction of PEEK powder added into the ethanol/isopropanol media (ethanol 95 vol\% and 2-propanol 5 vol\%) was $3 \%$

5 min, and (iii) cooling from $380^{\circ} \mathrm{C}$ to ambient temperature at a rate of $2{ }^{\circ} \mathrm{C} \mathrm{min}-1$. The nomenclature for the PEEK and PEEK/RGO coatings is indicated in Table 3.

\section{Coating characterization}

\section{Scanning electron microscopy}

The morphology of coatings was examined by scanning electron microscopy (SEM), using a field-emission scanning electron microscope ZEISS Gemini SEM 450 (ZEISS, Germany) equipped with an in-lens secondary electron detector. Graphene oxide is highly electron transparent because of its 2D structure and low atomic number, especially at high accelerating voltages when incident electrons can pass through the nanosheets more easily [32]. Hence, an accelerating voltage of $1 \mathrm{kV}$ and probe current of $10 \mathrm{nA}$ were selected to favor the observation of GO nanosheet details and to ensure a reliable comparison between different coatings. Prior to SEM characterization, the samples were dried at $60{ }^{\circ} \mathrm{C}$ for $24 \mathrm{~h}$ in a drying oven with natural convection (DL 115 DRYline ${ }^{\circledR}$, VWR International BVBA, Belgium) and subsequently coated with $\mathrm{Au}$ in a sputter coater (Q150T S Plus, Quorum, UK) to prevent the sample charging during measurement.

\section{Atomic force microscopy}

Topography was examined and phase images of the surface of PEEK and PEEK / RGO nanocomposite coatings were obtained using an atomic force microscope (AFM) Innova ${ }^{\circledR}$ (Bruker, Germany) in standard dynamic mode, which was provided with 20-bit DAC 
scan control and nanosensor tapping mode probes $\mathrm{NCHV}{ }^{\circledR}$. An effective resonance frequency of $160 \mathrm{kHz}$ and a constant nominal force of $48 \mathrm{~N} \mathrm{~m}^{-1}$ were considered. Areas of $1 \times 1 \mu^{2}$ and $10 \times 10$ $\mu \mathrm{m}^{2}$ were scanned with a resolution of $1024 \times 1024$ pixels at a scan speed of $10 \mu \mathrm{m} / \mathrm{s}$. AFM micrographs were processed in the NanoScope ${ }^{\circledR}$ software (version 1.4).

\section{Confocal laser scanning microscopy}

Roughness was characterised in accordance with the ISO 251587-2:2012 by using confocal laser scanning microscopy (CLSM). A confocal microscope Sensofar Sneox (Sensofar, Germany) that incorporated an objective EPI $50 \times$ and a high-resolution chargecoupled sensor $(0.26 \mu \mathrm{m} /$ pixel resolution, and $1360 \times 1024$ pixels area) allowed the generation of two-dimensional (2D) and three-dimensional (3D) images of the PEEK-based coatings. Non-contact optical profiles of observable areas $(350.88 \times 264.19$ $\mu \mathrm{m}^{2}$ ) were recorded by considering a $30 \mathrm{~s}$ acquisition time and $8.5 \%$ light intensity. Roughness was evaluated over the total surface and in the characteristic areas of the samples: flat areas between the pores and inside the pores. To quantify the surface roughness, the arithmetical mean deviation (Sa) and the root mean square height $(\mathrm{Sq})$ were used. SensoMAP Premium ${ }^{\circledR}$ software (version 7.4.8114) was used for analyzing the experimental data.

\section{Simultaneous thermal analysis}

Thermogravimetric analysis-differential thermal analysis (TGA-DTA), and differential scanning calorimetry-thermogravimetric analysis (DSC-TGA) were performed in a simultaneous thermal analyzer STA 449 F1 Jupiter (NETZSCH-Gerätebau $\mathrm{GmbH}$; Germany). Samples of PEEK/RGO coatings were prepared for the TGA-DTA and DSC-TGA analyses as follows: after EPD, coatings were dried in an air atmosphere at $150{ }^{\circ} \mathrm{C}$ for $3 \mathrm{~h}$, and carefully detached from the metallic substrate using a spatula and placed on aluminum foil. Then, the samples were thermally treated under the same conditions used for the coatings. Finally, the aluminum foil was completely removed using precision pliers.

For TGA-DTA measurements, $10 \mathrm{mg}$ of PEEK/ RGO samples was placed into $\mathrm{Al}_{2} \mathrm{O}_{3}$ crucibles of $8 \mathrm{~mm}$ diameter and $365 \mu \mathrm{L}$ volume (BRISK Tábor a.s.;
Czech Republic) and measured in air atmosphere (flow of $25 \mathrm{~mL} \mathrm{~min}^{-1}$ ) under linear dynamic conditions from 100 to $800{ }^{\circ} \mathrm{C}$ at a constant heating rate of $10 \mathrm{C} \mathrm{min}^{-1}$. For every individual sample measurement, the result was corrected by considering the baseline associated with the empty $\mathrm{Al}_{2} \mathrm{O}_{3}$ crucible test that was recorded under the same experimental conditions as the sample. The nanofiller mass fraction (RGO wt\%) was measured and the onset decomposition temperature, $T_{\text {onset }}$ was determined by the extrapolation of two tangential lines of the TGA curve.

The effect of RGO on the melting and crystallization of PEEK was studied in DSC-TGA mode. PEEK/ RGO samples ( $10 \mathrm{mg}$ ) were sealed in $80 \mu \mathrm{L}$ platinum crucibles and measured under flowing nitrogen atmosphere $\left(25 \mathrm{~mL} \mathrm{~min}^{-1}\right)$. The DSC-TGA measurements comprised four stages: (1) heating at a constant rate of $10{ }^{\circ} \mathrm{C} \mathrm{min}{ }^{-1}$ from 100 to $380{ }^{\circ} \mathrm{C}$, (2) isothermal stage at $380{ }^{\circ} \mathrm{C}$ during $5 \mathrm{~min}$, (3) cooling at a constant rate of $2{ }^{\circ} \mathrm{C} \mathrm{min}^{-1}$ from 380 to $100{ }^{\circ} \mathrm{C}$, and (4) a second heating at a constant rate of $10{ }^{\circ} \mathrm{C} \mathrm{min}{ }^{-1}$ from 100 to $380{ }^{\circ} \mathrm{C}$. The measurement of every sample was corrected by considering the blank curve that was previously recorded for the empty platinum crucible. Transition glass temperature, $T_{g}$, was determined from the step in the baseline of the corrected sample measurement and associated with the temperature at which the half point of the angle bisector determined by the tangents drawn on the heat flow curve above and below the transition temperature. Melting temperature, $T_{m}$, was considered as the temperature of the maximum deviation of the melting endotherm with respect to the baseline. The crystallization temperature, $T_{c}$, was that associated with the minimum in the crystallization exotherm. The apparent enthalpy of the transition, $\Delta H_{\mathrm{ap}}$, was determined from the corresponding transition area, taking the upper and lower limits of the integration at the corresponding deviations from the baseline of the thermogram. The degree of crystallinity, $\chi$, was calculated from the expression:

$\chi=\frac{\Delta H_{\mathrm{ap}}}{w \cdot \Delta H_{0}}$

where $\Delta H_{\text {ap }}$ is the apparent enthalpy of the transition, $w$ is the weight fraction of RGO nanosheets, and $\Delta H_{0}$ is the melting enthalpy of $100 \%$ crystalline PEEK, for which a value of $130 \mathrm{~J} / \mathrm{g}$ was adopted [33]. 


\section{Grazing incidence angle X-ray diffraction}

A parallel beam geometry was used for performing grazing incidence angle X-ray Diffraction (GIAXRD) on the PEEK-based nanocomposite coatings. Diffraction patterns were recorded using a Panalytical Empyrean DY1098 X-ray diffractometer (Malvern Panalytical Ltd, Netherlands) operated at $45 \mathrm{kV}$ and $40 \mathrm{~mA}$. The instrument was equipped with a conventional line focus $\mathrm{Cu}$ radiation tube, a parabolic Göbel mirror, and a 2D solid-state hybrid pixel X-ray PIXcel3D detector switched to proportional counter mode ( 1 channel open). In addition, $1 / 4^{\circ}$ divergence fixed slit and $10 \mathrm{~mm}$ fixed mask were considered for limiting the penetration depth and beamwidth, respectively. The resulting intense quasi-parallel incident X-ray beam irradiated the stainless-steel substrates (dimensions of $15 \mathrm{~mm} \times 15 \mathrm{~mm}$ ) coated with the PEEK or PEEK/RGO nanocomposites. Background radiation was significantly reduced by using a $0.18^{\circ}$ parallel plate collimator, and $\mathrm{K} \beta$ X-ray spectral line of $\mathrm{Cu}$ was suppressed by Nickel filter, maximizing the intensity of the $\mathrm{Cu}-\mathrm{K} \alpha$ radiation $(\lambda=1.5406 \AA)$. GAXRD patterns were recorded in the angular range (20) from 5 to $40^{\circ}$ in step-scan mode which comprised increments of $0.026^{\circ}$ and accumulated counts for each step of $10 \mathrm{~s}$. With the aim of analyzing the crystalline phase changes at the proximity of the coating surface, the angle of incidence was set to $0.2^{\circ}$ and $1^{\circ}$ to vary the penetration depth. In addition, to determine the position and index of the characteristic diffraction peaks associated with the polymeric matrix and the nanofiller, the crystallinity degree of the PEEK matrix was estimated from the XRD diffractograms $[33,34]$.

\section{Results and discussion}

In the first part of this section, the main morphological features of PEEK/RGO nanocomposite coatings are discussed and their relationship with the chemical composition and microstructure is presented. Subsequently, the effect of the chemical composition on the melting and non-isothermal crystallization processes of PEEK is analyzed paying special attention to the relation between the microstructural characteristics and morphology.

\section{Microstructure characterisation}

The spherulitic morphology of PEEK formed during non-isothermal crystallization from the melt is heavily dependent on factors such as molecular weight, nucleation site, and seed density, and thermal treatment. Whilst fast cooling rates contribute to low crystallinity, slow rates promote the development of large spherulites. Spherulites that resulted from the slow cooling rate $\left(2{ }^{\circ} \mathrm{C} \mathrm{min}{ }^{-1}\right)$ from melt are observed in the SEM micrographs of PEEK-C in Fig. $2 a$ and $b$. PEEK-C spherulite size was in the range of tens to hundreds of microns, in agreement with that described in PEEK films [21].

In PEEK/RGO nanocomposite coatings, the nanofiller induced three distinctive morphological features: (i) a large-scale co-continuous morphology formed by the nanosheets, (ii) dendritic PEEK domains, and (iii) irregular domains related to the deposition of PEEK particles wrapped by the nanosheets. The large-scale co-continuous morphology suggests an assembly of the GO nanosheets that occurred during the EPD process, resulting in deposited nanosheets whose basal planes are aligned with the coating surface, as seen in Fig. 3a. The high electron transparency of the GO nanosheets, which is the consequence of their structure and low atomic number [32], allows deposited PEEK particles to be visualised underneath. After the thermal treatment that led to the PEEK/RGO nanocomposites by densifying the polymeric matrix and reducing the GO, the originally formed large-scale co-continuous morphology was retained, as observed in Fig. 3b. Other interesting morphological features of PEEK/ RGO nanocomposite coatings are indicated in the SEM micrograph in Fig. $3 \mathrm{~b}$ and further discussed below.

A representative dendritic domain such as that shown in Fig. $3 \mathrm{~b}$ is illustrated in more detail in the SEM micrograph in Fig. 4. The formation of such domains was closely connected with the large-scale co-continuous ones, by being deposited on RGO nanosheets. Such dendritic PEEK morphology could emerge from two mechanisms that took place during the cooling from melt. The first mechanism, transcrystallinity or surface crystallisation, is a condition where crystals grow normal to an existing surface that serves as nuclei, in the present case, the RGO nanosheets. Transcrystallinity of PEEK provoked by heterogenous nucleation on diverse surfaces is a well- 

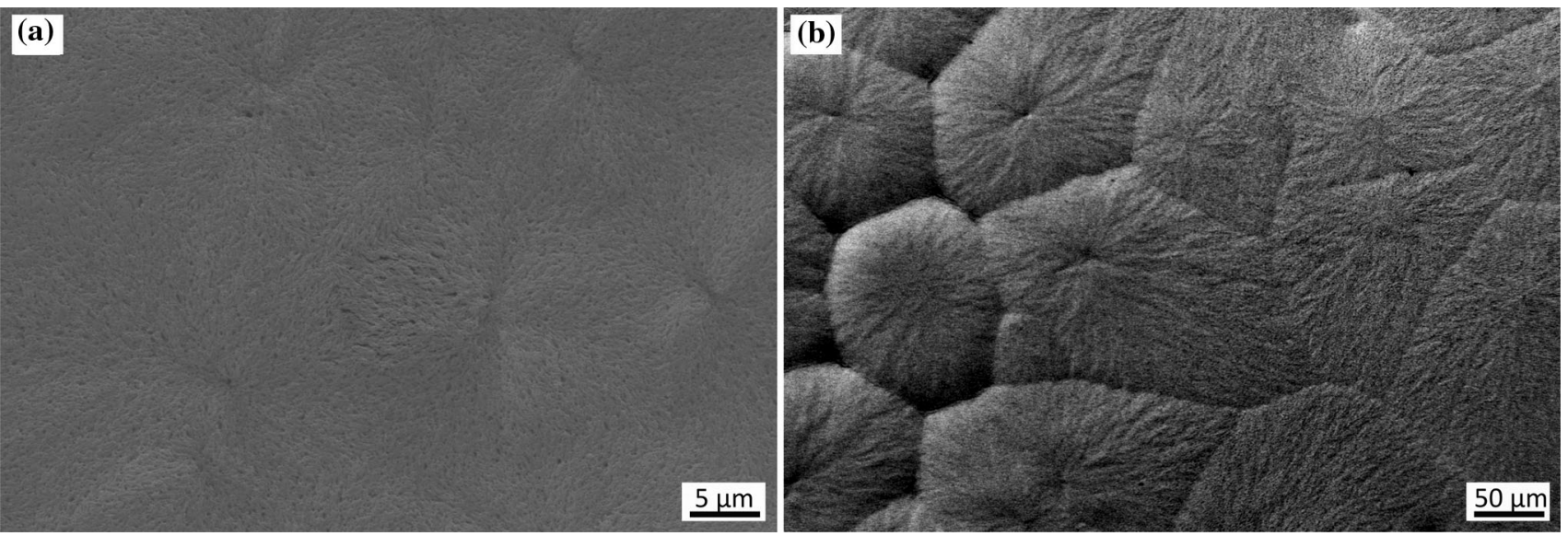

Figure 2 SEM micrograph of PEEK-C. Spherulites ranging from tens a to hundreds $\mathbf{b}$ of microns are distinguished.
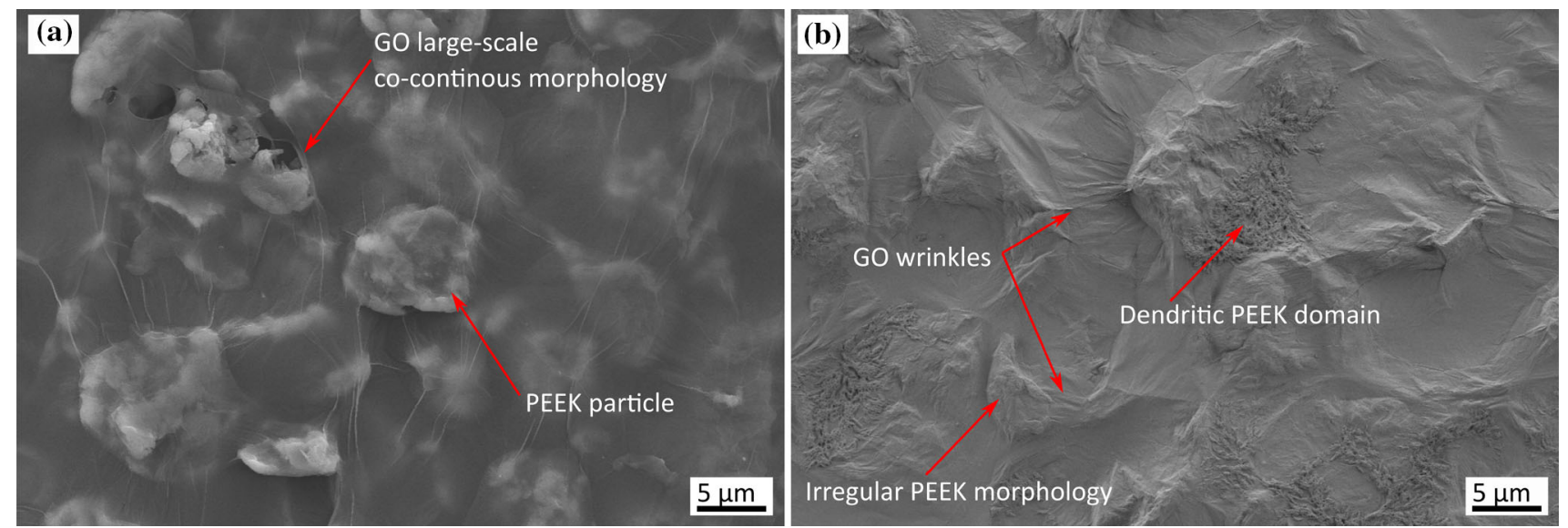

Figure 3 SEM micrographs of the large-scale co-continuous morphology a before and $\mathbf{b}$ after the thermal treatment. Other interesting morphological features were observed alongside the large-scale co-continuous morphology after the thermal treatment, as indicated in (b).

known phenomenon [10, 21, 23, 24]. The second mechanism is related to crystal growth rate in thin films, in which transcrystalline growth could compete with the bulk spherulitic one for developing the crystalline phase depending, in a first instance, on the surface energy and interfacial free energy difference and, later on, the kinetics of crystallization [21, 28]. However, in the dendritic PEEK domains in PEEK/ RGO nanocomposite coatings the suppression of bulk spherulitic growth was evident. Thus, the dendritic domains are obliged to grow perpendicularly to the surface, developing a thickness less than $1 \mu \mathrm{m}$, as observed in Fig. 4.

The irregular PEEK morphology is associated with the nanosheet wrapping effect during the EPD process [10]. RGO wrinkles that result from the thermal reduction effect and the van der Waal's interactions [35], as well as irregular PEEK domains, are

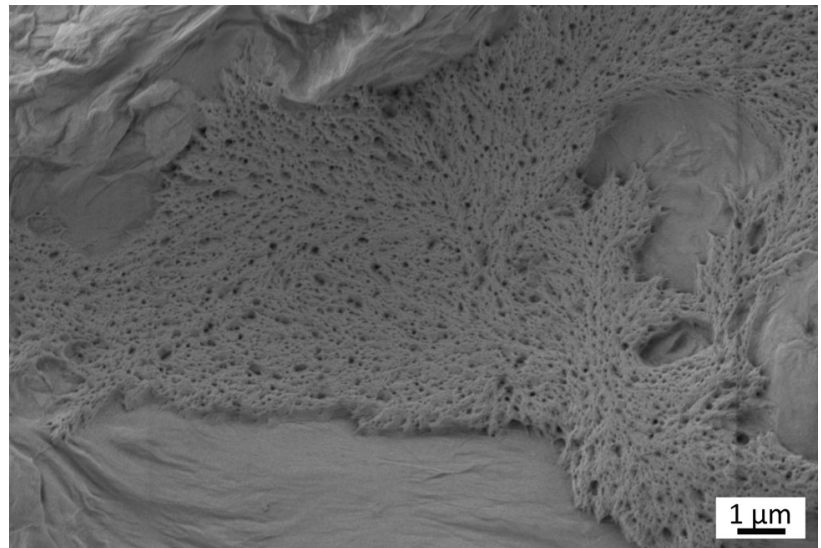

Figure 4 Representative SEM micrograph of a dendritic PEEK domain.

distinguished in Fig. 3b. To gain further insights into the effect of RGO on the irregular PEEK domains, 

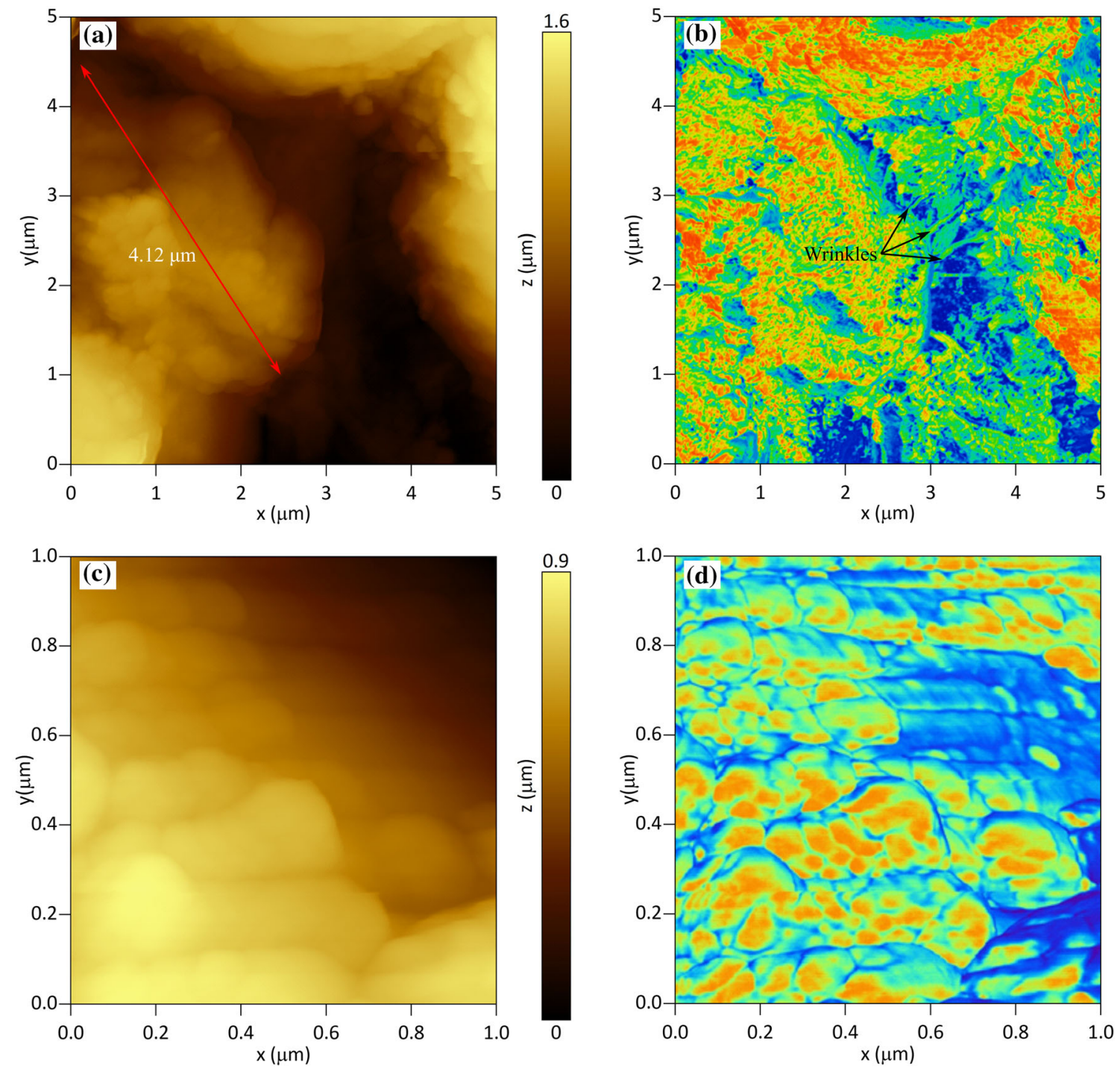

Figure 5 AFM topography (left) and phase (right) images. An irregular PEEK domain (a), and surface stiffness/softness characteristics of the irregular PEEK domain and RGO wrinkles (b) are distinguishable in the scanned area of $5 \times 5 \mu \mathrm{m}^{2}$. The

AFM topological and phase imaging were carried out. In Fig. 5a, an AFM topology image of a scanned area $\left(5 \times 5 \mu^{2}\right)$ shows an irregular PEEK domain with dimensions (approximately $4 \mu \mathrm{m}$ length) comparable with that indicated in Fig. 3b. Surface stiffness/softness characteristics of the irregular PEEK domain and RGO wrinkles can be differentiated in the AFM phase imaging presented in Fig. $5 \mathrm{~b}$. The AFM topology image collected over a smaller area $\left(1 \times 1 \mathrm{~m}^{2}\right)$, Fig. $5 \mathrm{c}$, indicated an analogous morphology to that reported for the graphene oxide reduction of thin films [36]. Nevertheless, the corresponding AFM phase image, Fig. 5d, revealed

AFM topography and image collected over an area of $1 \times 1 \mu \mathrm{m}^{2}$ show with more detail the morphology of RGO (c) and inner PEEK granular structure (d), respectively.

granular structures in the order of one hundred of nanometres (indicated in orange). The flake size is several orders of magnitude larger $(0.5-2.0 \mu \mathrm{m})$, so consequently, these inner granular structures could be related to PEEK. Large granular and small crystals of melt crystallised PEEK have recently been described [37], but this is the first time that this is reported for PEEK/RGO systems. As discussed further on the basis of the GIAXRD results, a transcrystalline growth into the irregular PEEK domains could develop on the RGO nanosheets, whilst spheruliticlike domains develop at the interior of the irregular PEEK domains distant from the nanosheets. 


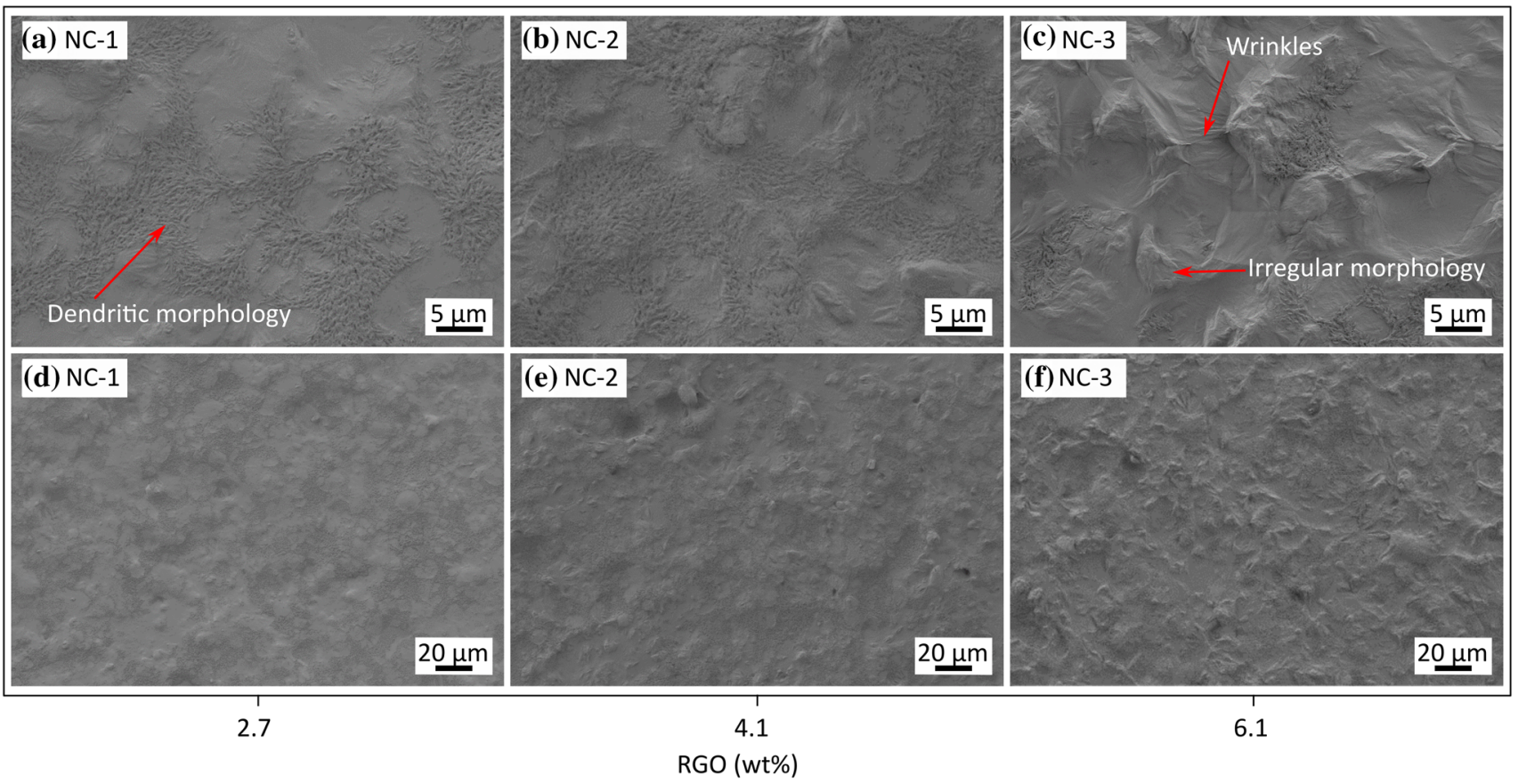

Figure 6 SEM micrographs of PEEK/RGO nanocomposites NC1 , NC-2, and $\mathrm{NC}-3$. The RGO $\mathrm{wt} \%$ is indicated in the $x$-axis. Variations in the superficial dendritic and irregular PEEK

It is expected that the aforementioned morphologies depend largely on the nanosheet content. Dendritic and irregular PEEK morphologies are compared in Fig. 6 for the nanocomposites NC-1, $\mathrm{NC}-2$, and NC-3. From the residual mass in the thermogravimetric curves (Fig. S1), the RGO wt\% was estimated to be 2.7, 4.1, and 6.1 for the nanocomposite coatings NC-1, NC-2, and NC-3, respectively (RGO wt\% values are indicated in the $x$ axis in Fig. 6). These nanosheet mass fractions were indeed larger than those utilized in preparing the EPD suspensions (GO to PEEK in Table 3), and they could be related to the difference in the charge and the electrophoretic mobility between the PEEK particles and GO nanosheets during the EPD process [38]. The highest nanosheet content (6.1 RGO wt\%) inhibits the development of the dendritic PEEK morphology, as seen in Fig. 6c. By contrast, the irregular PEEK morphology evolves favorably by increasing the RGO wt\%. The already mentioned morphological features were representative along the sample surface, Fig. $6 \mathrm{~d}$ to $\mathrm{f}$, contributing to the roughness.

Figure 7a to $\mathrm{d}$ show the confocal images of the surface for the PEEK-C and PEEK/RGO nanocomposite coatings. PEEK spherulites are observed in the morphology are observed as a function of RGO $\mathrm{wt} \%$. Wrinkles on RGO nanosheets are also indicated.

confocal image of PEEK-C in Fig. 7a. On the contrary, the CLSM did not confirm the formation of PEEK spherulites in the nanocomposite coatings, Fig. $7 \mathrm{~b}$ to d. As a result, the roughness could be modified by adding RGO. The values of the roughness parameters $S_{\mathrm{a}}$ and $S_{\mathrm{q}}$ summarised in Fig. 7e increased with the RGO content due to irregular PEEK morphology. The changes in $S_{\mathrm{a}}$ and $S_{\mathrm{q}}$ showed a similar trend, but the increment was more pronounced for $S_{\mathrm{q}}$ when comparing PEEK-C and NC-3.

\section{Melt and non-isothermal crystallization}

Figure 8a displays the first heating scan in a nitrogen atmosphere from 100 to $380{ }^{\circ} \mathrm{C}$ at the constant heating rate of $10{ }^{\circ} \mathrm{C} \mathrm{min} \mathrm{min}^{-1}$ for the PEEK-C. Above $145^{\circ} \mathrm{C}$, the baseline of the differential thermogram starts changing, and the glass transition is observed at $T_{g}=163{ }^{\circ} \mathrm{C}$. The $T_{g}$ value depends on the thermal history and the physical method that is implemented for its measurement $[39,40]$. However, the $T_{g}$ value measured in this work agrees with that obtained in the study of annealing of PEEK with different molecular weight using DSC [41]. Further increase of temperature provokes the melting of the PEEK crystalline phase, resulting in a large and broad 


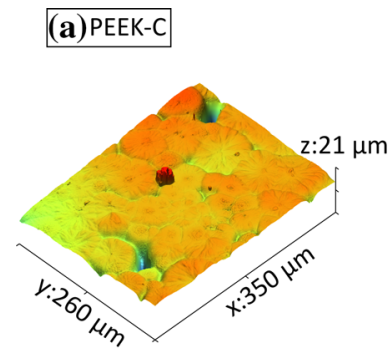

(c) NC-2

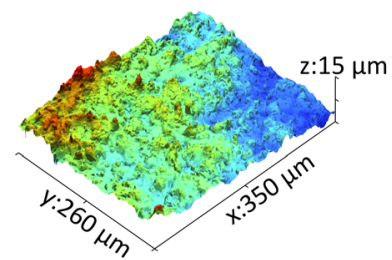

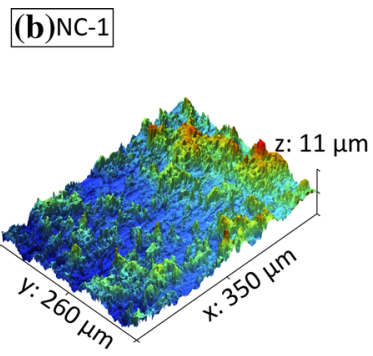

(d)NC-3

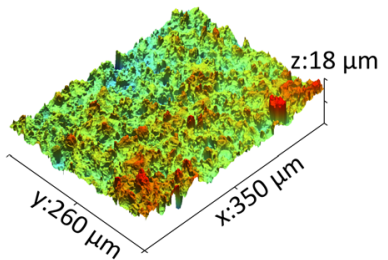

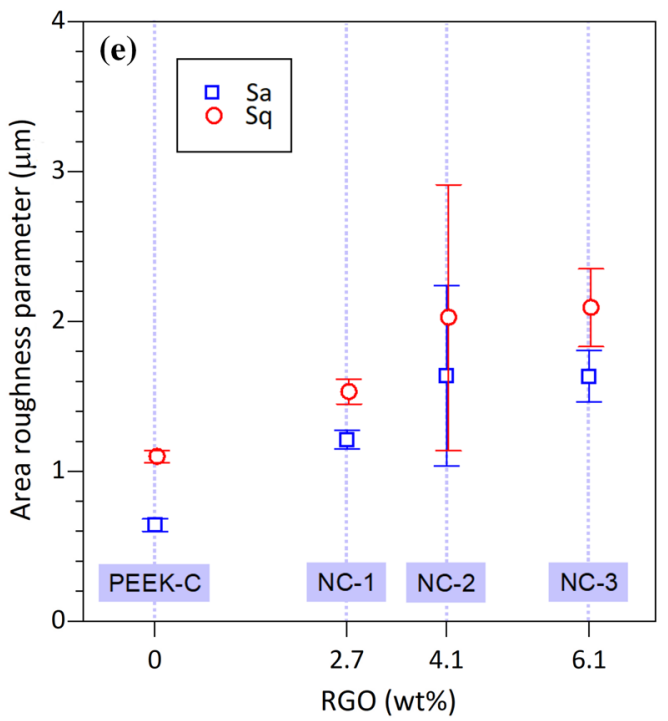

Figure 7 Confocal microscope images of PEEK-C and NC-1, NC-2, and NC-3 nanocomposite coatings ((a) to (d)), and their Sa and Sq roughness parameters $(\mathbf{e})$.

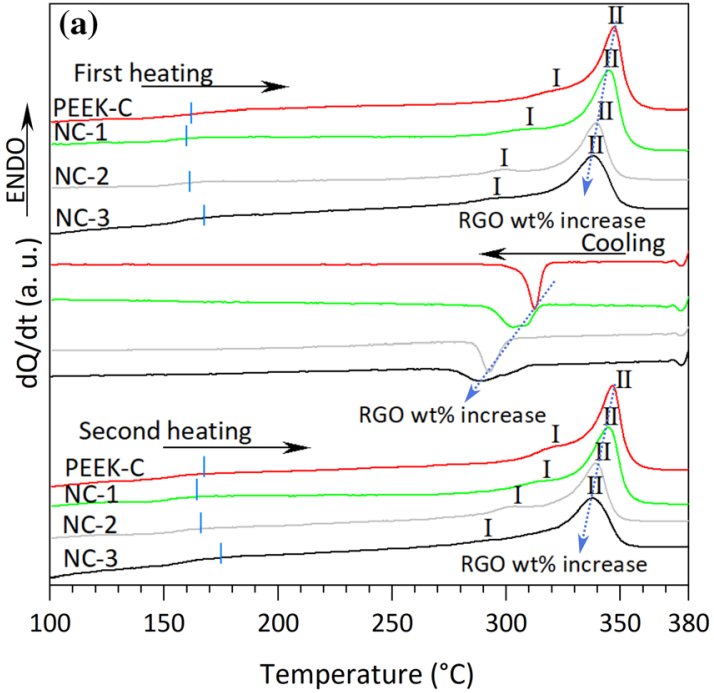

Figure 8 a Differential thermograms of PEEK and PEEK/RGO nanocomposite coatings in nitrogen atmosphere during (i) first heating from $30{ }^{\circ} \mathrm{C}$ to $380{ }^{\circ} \mathrm{C}$ at $10{ }^{\circ} \mathrm{C} \mathrm{min}{ }^{-1}$, (ii) cooling from $100{ }^{\circ} \mathrm{C}$ to $35^{\circ} \mathrm{C}$ at $2{ }^{\circ} \mathrm{C} \mathrm{min}{ }^{-1}$, and (ii) second heating from

endotherm centerd at $T_{m, I I}=347^{\circ} \mathrm{C}$ (region II) with a shoulder at $T_{m, ~}{ }_{I}=321{ }^{\circ} \mathrm{C}$ (region I). PEEK endothermic response is of complex nature and involves diverse factors such as molecular weight, crystallization history, time and temperature associated with annealing process, and scanning heating rate [41-46]. The PEEK-C endotherm shoulder in region I, Fig. 8a, corresponds to the melting of a small

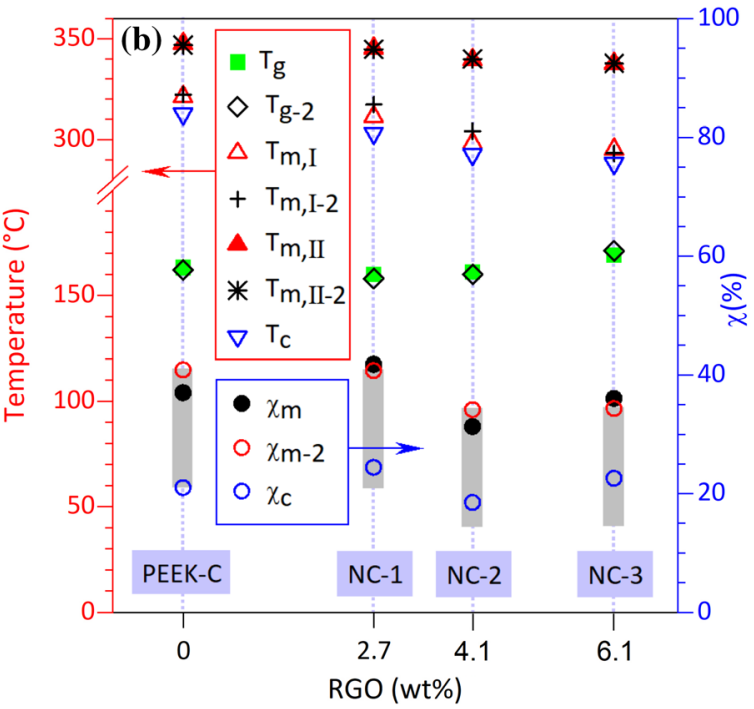

$30{ }^{\circ} \mathrm{C}$ to $380{ }^{\circ} \mathrm{C}$ at $10{ }^{\circ} \mathrm{C} \mathrm{min}{ }^{-1}$. b Parameters associated with the melting and non-isothermal crystallization of the PEEK-based coatings as a function of the RGO content (wt\%).

population of crystals that are developed during the DSC scan, while the endotherm peak in the region II represents the melting of the majority population of crystals that are formed during the non-isothermal crystallization of the PEEK-C from the melt [41].

On cooling from the molten state, nucleation and crystal growth takes place, and the crystalline microstructure is developed under non-isothermal 
conditions. The exothermic peak is observed at $305{ }^{\circ} \mathrm{C}$ in the differential thermogram recorded at a constant cooling rate of $2{ }^{\circ} \mathrm{C} \mathrm{min}^{-1}$ from 380 to $100{ }^{\circ} \mathrm{C}$ in nitrogen atmosphere, Fig. 8a. This $T_{c}$ value agrees with those reported in the literature [44, 45]. A subsequent heating scan of PEEK-C under identical experimental conditions is also shown in Fig. 8a. The glass transition, and endothermic shoulder and peak temperatures $\left(T_{g-2}, T_{m, \mathrm{I}-2}\right.$, and $\left.T_{m, \mathrm{II}-2}\right)$ are clearly distinguished in the differential thermogram. Although the values of the aforesaid parameters remained almost unchanged through the first and second heating scan, a slightly better defined exothermic shoulder in the second scan in Fig. 8a contributed to a minor increment of $\chi_{m-2}$ with respect to $\chi_{m}$, as shown in and Fig. 8 (b). Nevertheless, the values of degree of crystallinity $\chi_{m}$ and $\chi_{m-2}$ were in the interval of 30-40\% described for PEEK [33, 34, 47]. On the contrary, the crystallinity degree related to the exotherm $\left(\chi_{c}\right)$ and that associated with the second heating-scan endotherm $\left(\chi_{m-2}\right)$ substantially differed from each other, as seen in Fig. 8b. This difference arises from the recrystallization process that takes place during the DSC scan [41].

Incorporation of nano- and micro fillers in PEEK could affect its melting and crystallization processes $[18,19]$. The differential thermograms in Fig. 8a confirmed that RGO influenced the melting and crystallization behaviour of PEEK. These results were consistent with the observed changes in the morphology, that is, the development of dendritic PEEK morphology, the absence of spherulites in the PEEK/ RGO nanocomposites, and the inner granular structures in the irregular PEEK domains. In the first and second heating scans in Fig. 8a, the dotted arrows indicate the shift to lower temperature of the large and broad endotherm with the increase of the content of RGO wt.\% to $6.1 \mathrm{wt} \%$ for NC-3. The shift of the endothermic shoulder to lower temperatures was even more significant, as documented by the comparison of $T_{m, \mathrm{I}}$ and $T_{m, \mathrm{I}-2}$ parameters with $T_{m, \mathrm{II}}$ and $T_{m, I I-2}$ in Fig. $8 b$. On the contrary, the glass transition temperatures of the first and second scan $T_{\mathrm{g}}$ and $T_{\mathrm{g}-2}$, respectively, increased for nanosheet content above $4.1 \mathrm{wt} . \%$ RGO. Nonetheless, the temperature variations of $T_{\mathrm{g}}$ and $T_{\mathrm{g}-2}$ were of similar order of magnitude as those of $T_{m \text {-I }}$ and $T_{m \text {-II }}$ as shown in Fig. $8 \mathrm{~b}$. This result implies that high RGO concentrations substantially inhibited the mobility of the PEEK polymeric chains, provoking changes in the PEEK glass transition, and in the reorganisation of the polymeric chains in crystals during the heating scan.

The hindering of polymer chain mobility induced by RGO is well known [48, 49]. Crystallization from the melt with low chain mobility generally results in an imperfect crystal structure [41]. The differential thermograms of the cooling scan in Fig. 8a indicated a shift of the exotherm to lower temperatures with the increasing RGO content. Figure $8 \mathrm{~b}$ presents the effect of RGO on the estimated crystallinity of the exotherm $(\chi c)$. A slight increment of this parameter was observed at $2.7 \mathrm{wt} . \%$ of RGO, while at higher nanofiller content the crystallinity decreased. Crystallization and melting processes are intimately linked. Figure $8 \mathrm{~b}$ shows that $\chi_{c}$ had a variation trend similar to $\chi_{m}$ and $\chi_{m-2}$. By using the difference between the $\chi_{c}$ and $\chi_{m-2}$ of PEEK-C as a reference (vertical bar in Fig. 8b), it was found that $\chi_{c}$ and $\chi_{m-2}$ values converge in the nanocomposite coatings, reaffirming the effect of RGO on the mobility of the PEEK polymeric chains and its reorganization.

As in other semicrystalline polymers, the properties of PEEK depend heavily on the crystalline microstructure. Thus, a control of the thermal treatment is critical for optimising and obtaining desirable properties of a polymer. Depending on the atmosphere, the molecular weight and crystallinity of PEEK could be diminished by using prolonged heating at temperatures higher than $T_{m}$ [43-45]. In the preparation of PEEK-C and PEEK/RGO nanocomposite coatings, no significant difference between the parameters of the first and second DSC scan was observed, Fig. 8a and b, even though the measurements were performed under a nitrogen atmosphere and the thermal treatment of the samples was carried out in air. Considering both the DSC and TG results (Fig. S1), an excellent control of the thermal treatment was achieved.

Although the crystalline phase in bulk semicrystalline polymers is mainly determined by spherulitic growth [50], transcrystallity could significantly influence the development of the crystalline phase in thin films [21, 28]. Crystalline microstructure characteristics, for instance, crystallinity degree and crystal orientation, vary from bulk to interface because transcrystalline growth competes with the bulk spherulitic growth, concurrently occupying the volume of the material [28]. In this regard, the GIAXRD characterization of thin and ultrathin films by irradiating the sample at an extremely low 
incident angle with the aim of discriminating between multiple underlying structures that could contribute to the diffractogram pattern enables the determination of the characteristics of the crystalline microstructure at the proximity of the coating surface. So far, to the author's knowledge, GIAXRD has not been implemented in the characterization of PEEK-based coatings prepared by EPD. Figure 9 shows representative GIAXRD diffractogram patterns of the NC-3 (6.1 wt\% RGO) recorded at the incident angles of 0.2 and $1.0^{\circ}$. PEEK is characterized by an orthorhombic unit cell that is a result of its planar zig-zag conformation $(-\mathrm{R}-\mathrm{O}-\mathrm{R}-\mathrm{O}-\mathrm{CO})$ alignment with the $c$-axis, giving rise to four characteristic peaks at the approximate $2 \theta$ values of $19^{\circ}, 21^{\circ}$, $23^{\circ}$, and $29^{\circ}$, which are indexed as the (110), (111), (200), and (211) crystalline planes, respectively [45]. With respect to RGO, intercalation and exfoliation play a major part in the resulting XRD patterns of two-dimensional graphitic nanosheets because the distance between the layers could be altered [51, 52]. In Fig. 9, the crystalline plane (002) that is associated with the distance between RGO nanosheets was absent in the measured $2 \theta$ interval. Consequently, there is no contribution of the RGO structure to the GIAXRD diffractogram, allowing the estimation of the degree of crystallinity of the polymeric matrix in the PEEK/RGO nanocomposite coatings from XRD experimental data. On the other hand, the diffraction

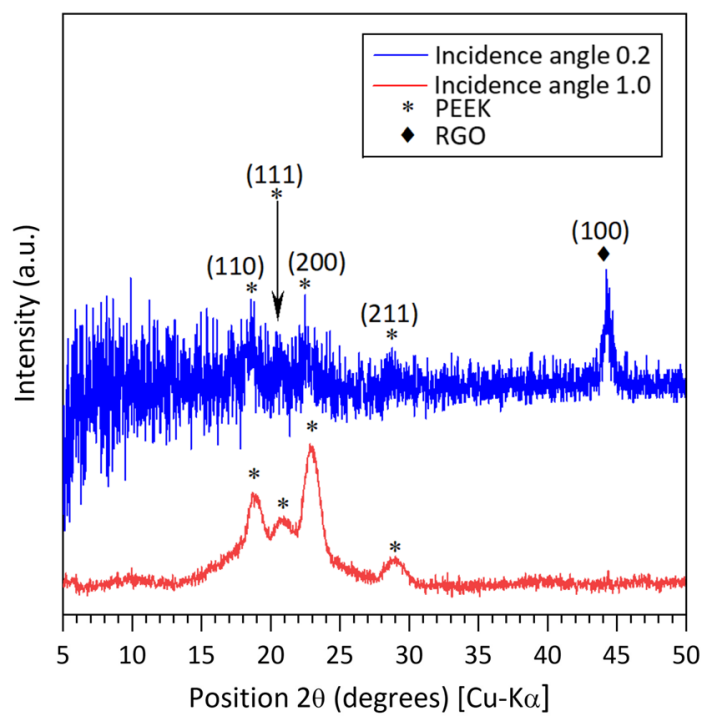

Figure 9 GIAXRD diffractogram patterns of the nanocomposite NC-3 (6.1\%wt RGO) recorded at the incident angles of 0.2 and $1.0^{\circ}$. peak assigned to the (100) crystalline plane is found in the GIAXRD diffractogram recorded at the lower incident angle.

In contrast with the (110) plane, the GIAXRD diffractograms recorded at an incident angle of $1^{\circ}$ (Fig. 10a) indicate that the diffraction intensity at the plane (200) markedly increased with the content of RGO. Two- and three-dimensional carbon-based structures could induce transcrystallinity or surface crystallisation in polymeric matrices, which in turn results in variations in XRD diffractogram intensities $[10,21,23,24]$. These results agree with the dendritic PEEK domains and inner granular structures in the irregular PEEK domains. Figure 10b compares the crystallinity degree of the PEEK-based nanocomposite coatings estimated from GIAXRD measurements as a function of the RGO content. The crystallinity degree, $\chi_{\text {-XRD }}$, decreases with increasing RGO content, having a maximum at $2.7 \mathrm{wt} \%$ RGO. The crystallinity degree derived from the DSC results $\left(\chi_{-}\right.$ DSC) is shown in Fig. 10b. Apart from the small deviation in the nanocomposite NC-3, a good match was found between GIAXRD results and DSC experimental data in estimating the PEEK crystallinity degree. The full width at the half maximum (FWHM) values of the peaks associated with the PEEK crystalline planes increased with increasing RGO content (Fig. 10b) except for the plane (200). FWHM is sensitive to microstructure alterations and varies inversely with the size of crystals, thus an increase of FWHM values implies a reduction of the crystallite size. A marked transcrystallinity at high RGO contents and the reduction of the PEEK crystallite size found by the GIAXRD measurements confirm the hindering effect of RGO on the mobility of the polymeric chains and its reorganization, in agreement with the results of the DSC analysis.

To analyze in greater detail the irregular PEEK domains that were predominant in the NC-3 (6.1 RGO wt\%), GIAXRD diffractograms were recorded at the incident angles in the interval $1-5^{\circ}$. The diffractograms are presented in Fig. 11a. The intensity of the diffraction line corresponding to the (110) plane is lower than that of the (200) plane for values below $3^{\circ}$. At $4^{\circ}$ the intensity of the diffraction lines of the (110) plane is higher and then decreases. Similarly, the crystallinity varies with the incident angle, however, its mean value is close to the estimated crystallinity from DSC measurements $(36 \%)$. The $\chi_{\text {-DSC }}$ is indicated in Fig. $11 \mathrm{~b}$ by the dotted horizontal line. This 
Figure 10 a GIAXRD diffractograms recorded at incident angle of $1^{\circ}$ for the PEEK-C and nanocomposite coatings, and $\mathbf{b}$ their crystallinity parameters.
Figure 11 GIAXRD diffractograms of NC-3 recorded at different angles of incidence (a), and their crystallinity parameters (b).
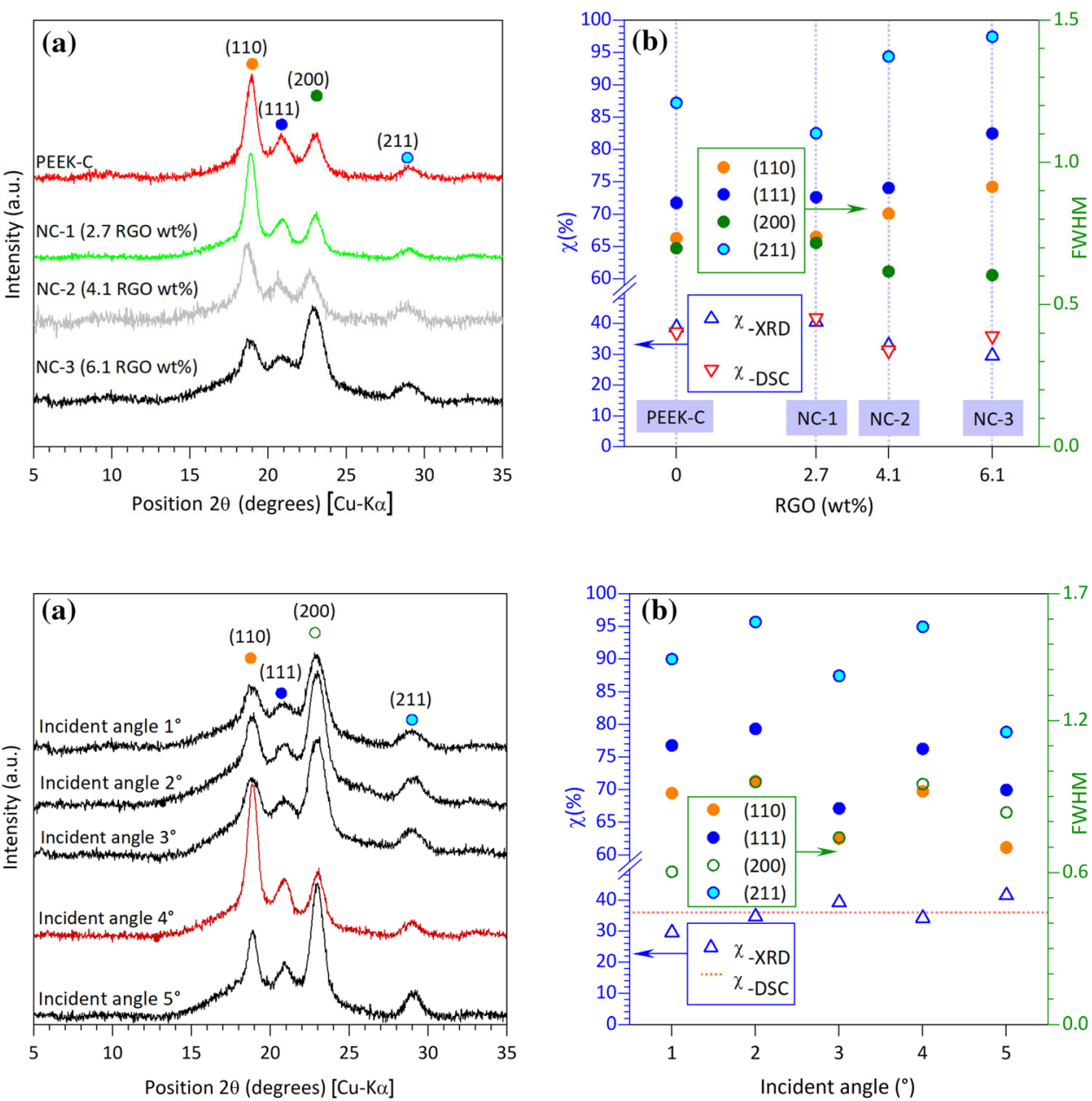

behavior in the GIAXRD diffractograms and their parameters, Fig. 11a and b, could be associated with the formation of a transcrystalline or granular PEEK structure inside the irregular PEEK domains at the proximity of the RGO nanosheets, whilst other crystalline structures could be formed away from the nanosheets. Further analysis is needed to clarify this point. It is expected that the changes in crystalline microstructure, e.g., degree of crystallinity and crystal orientation, will influence the tribological properties of PEEK/RGO nanocomposite coatings.

\section{Conclusions}

The correlations between chemical composition, morphology, and microstructure of poly(ether ether ketone)/reduced graphene oxide nanocomposite coatings were analyzed. The RGO nanosheet content played an important role in the resulting morphology, allowing modification of the surface roughness.
Moreover, the RGO content induced changes in the melting and non-isothermal crystallization of PEEK. Reduction of crystallinity degree and glass transition temperature in PEEK at high RGO contents was attributed to the low chain mobility impaired by the presence of the nanofiller. PEEK crystallinity degree estimated from GIAXRD experimental data, and the FWHM analysis agreed with DSC results, indicating a reduction of both the content of crystalline phase and the size of PEEK crystals with increasing RGO content. The dendritic PEEK morphology in PEEK/ RGO nanocomposite coatings was attributed to the effect exerted by the RGO nanosheets, as the suppression of bulk spherulitic growth was evident. GIAXRD diffractograms recorded at different incident angles indicate the formation of different crystal structures in the interior of irregular PEEK domains, albeit further analysis is required. 


\section{Acknowledgements}

Eduin I. González-Castillo gratefully acknowledges the National Council of Science and Technology (CONACYT, Mexico) for the postdoctoral scholarship (Reference: 239274) to carry out his project. Partial funding from the project FunGlass is acknowledged (European Union's Horizon 2020 research and innovation program under grant agreement No 739566). Yadir Torres expresses his gratitude to the Ministry of Science and Innovation of Spain (grant PID2019109371GB-I00). Peter S. Shuttleworth and Gary Ellis gratefully acknowledges the "Ministerio de Ciencia e Innovación" of Spain (Grant: PID2020117573GB-I00) funded by MCIN/AEI/10.13039/ 501100011033 and by the "European Union NextGenerationEU/PRTR". Michal Žitňan thanks the Centre for Functional and Surface Functionalized Glass (CEGLASS) (ITMS code is 313011R453) operational program Research and Innovation, co-funded by European Regional Development Fund.

\section{Funding}

Open Access funding enabled and organized by Projekt DEAL.

\section{Declarations}

Conflict of interest There is no conflict of interest.

Supplementary Information: The online version contains supplementary material available at http s:/ / doi.org/10.1007/s10853-022-06995-2.

Open Access This article is licensed under a Creative Commons Attribution 4.0 International License, which permits use, sharing, adaptation, distribution and reproduction in any medium or format, as long as you give appropriate credit to the original author(s) and the source, provide a link to the Creative Commons licence, and indicate if changes were made. The images or other third party material in this article are included in the article's Creative Commons licence, unless indicated otherwise in a credit line to the material. If material is not included in the article's Creative Commons licence and your intended use is not permitted by statutory regulation or exceeds the permitted use, you will need to obtain permission directly from the copyright holder. To view a copy of this licence, visit http://creativecommons.org/licen ses/by/4.0/.

\section{References}

[1] Kurtz SM (2012) Chapter 1-An overview of PEEK biomaterials. In: Kurtz SM (ed) PEEK biomaterials handbook. William Andrew Publishing, Oxford, pp 1-7

[2] Kurtz SM (2012) Chapter 6-Chemical and radiation stability of PEEK. In: Kurtz SM (ed) PEEK Biomaterials Handbook. William Andrew Publishing, Oxford, pp 75-79

[3] Sobieraj MC, Rimnac CM (2012) Chapter 5-Fracture, fatigue, and notch behavior of PEEK. In: Kurtz SM (ed) PEEK Biomaterials Handbook. William Andrew Publishing, Oxford, pp 61-73

[4] Babrauskas V, Fuoco R, Blum A (2014) Chapter 3-Flame retardant additives in polymers: when do the fire safety benefits outweigh the toxicity risks? In: Papaspyrides CD, Kiliaris P (eds) Polymer green flame retardants. Elsevier, Amsterdam, pp 87-118

[5] Wypych G (2012) PEKK polyetherketoneketone. In: Wypych G (ed) Handbook of polymers. Elsevier, Oxford, pp 367-369

[6] Sampaio M, Buciumeanu M, Henriques B, Silva FS, Souza JC, Gomes JR (2016) Tribocorrosion behavior of veneering biomedical PEEK to Ti6Al4V structures. J Mech Bio Mat 54:123-130. https://doi.org/10.1016/j.jmbbm.2015.09.010

[7] Boccaccini AR, Keim S, Ma R, Li Y, Zhitomirsky I (2010) Electrophoretic deposition of biomaterials. J R Soc Interface 7:S581-S613. http://doi.org/10.1098/rsif.2010.0156.focus

[8] Dickerson JH, Boccaccini AR (eds) (2012) Electrophoretic deposition of nanomaterials. Springer, New York. https://doi. org/10.1007\%2F978-1-4419-9730-2

[9] Corni I, Ryan MP, Boccaccini AR (2008) Electrophoretic deposition: From traditional ceramics to nanotechnology. J Euro Ceramic Soc 28(7):1353-1367.

[10] González-Castillo EI, Costantini T, Shaffer MSP, Boccaccini AR (2020) Nanocomposite coatings obtained by electrophoretic co-deposition of poly(etheretherketone)/graphene oxide suspensions. J Mater Sci.

[11] Feng H, Li Y, Li J (2012) Strong reduced graphene oxidepolymer composites: hydrogels and wires. RSC Adv 2(17):6988-6993

[12] Geim AK, Novoselov KS (2007) The rise of graphene. Nat Mater 6:183

[13] Compton OC, Nguyen ST (2010) Graphene oxide, highly reduced graphene oxide, and graphene: versatile building blocks for carbon-based materials. Small 6:711-723. http s://doi.org/10.1002/smll.200901934 
[14] Zhu Y, Murali S, Cai W, Li X, Suk JW, Potts JR, Ruoff RS (2010) Graphene and graphene oxide: synthesis, properties, and applications. Adv Mater 22(35):3906-3924

[15] Gómez-Navarro C, Meyer JC, Sundaram RS, Chuvilin A, Kurasch S, Burghard M, Kern K, Kaiser U (2010) Atomic structure of reduced graphene oxide. Nano Lett 10(4):1144-1148

[16] Cebe P, Chung SY, Hong S-D (1987) Effect of thermal history on mechanical properties of polyetheretherketone below the glass transition temperature. J Appl Polym Sci 33(2):487-503

[17] Damman P, Fougnies C, Moulin JF, Dosiere M (1994) Crystallinity of Poly(aryl ether ether ketone) by Vibrational Spectroscopy. Macromolecules 27.

[18] Kuo MC, Huang JC, Chen M (2006) Non-isothermal crystallization kinetic behavior of alumina nanoparticle filled poly(ether ether ketone). Mater Chem Phys 99(2):258-268

[19] Rong C, Ma G, Zhang S, Song L, Chen Z, Wang G, Ajayan PM (2010) Effect of carbon nanotubes on the mechanical properties and crystallization behavior of poly(ether ether ketone). Compos Sci Technol 70(2):380-386

[20] Nguyen HX, Ishida H (1986) Molecular analysis of the melting behaviour of poly(aryl-ether-ether-ketone). Polymer 27(9):1400-1405

[21] Waddon AJ, Hill MJ, Keller A (1978) On the crystal texture of linear polyaryls (PEEK, PEK and PPS). J Mater Sci 22:1773. https://doi.org/10.1007/BF01132406

[22] Regis M, Bellare A, Pascolini T, Bracco P (2017) Characterization of thermally annealed PEEK and CFR-PEEK composites: structure-properties relationships. Polym Degrad Stab 136:121-130

[23] Tewatia A, Hendrix J, Dong Z, Taghon M, Tse S, Chiu G, Mayo WE, Kear B, Nosker T, Lynch J (2017) Characterization of melt-blended graphene-poly(ether ether ketone) nanocomposite. Mater Sci Eng, B 216:41-49

[24] Lee Y, Porter RS (1986) Crystallization of poly(etheretherketone) (PEEK) in carbon fiber composites. Polym Eng Sci 26(9):633-639

[25] Liu K, de Boer EL, Yao Y, Romano D, Ronca S, Rastogi S (2016) Heterogeneous Distribution of Entanglements in a Nonequilibrium Polymer Melt of UHMWPE: Influence on Crystallization without and with Graphene Oxide. Macromolecules 49(19):7497-7509

[26] Xu J-Z, Liang Y-Y, Huang H-D, Zhong G-J, Lei J, Chen C, Li Z-M (2012) Isothermal and nonisothermal crystallization of isotactic polypropylene/graphene oxide nanosheet nanocomposites. J Polym Res 19(10):9975

[27] Schaefer DW, Justice RS (2007) How Nano Are Nanocomposites? Macromolecules 40(24):8501-8517
[28] Cho K, Kim D, Yoon S (2003) Effect of substrate surface energy on transcrystalline growth and its effect on interfacial adhesion of semicrystalline polymers. Macromolecules 36(20):7652-7660

[29] V.P. Solutions, 700 series electrostatic powder coatings product data sheet, 2018.

[30] V.M. Limited, VICOTE ${ }^{\mathrm{TM}}$ high temperature performance coatings, 2017.

[31] T.M.U. Ltd, Stainless Steel 316L 1.4404, 2018. https://www. thyssenkrupp-materials.co.uk/stainless-steel-3161-14404.h tml.

[32] Lightcap IV, Murphy S, Schumer T, Kamat PV (2012) Electron hopping through single-to-few-layer graphene oxide films. Side-selective photocatalytic deposition of metal nanoparticles. J Phys Chem Lett 3(11):1453-1458.

[33] Blundell DJ, Osborn BN (1983) The morphology of poly(aryl-ether-ether-ketone). Polymer 24(8):953-958

[34] Reitman M, Jaekel D, Siskey R, Kurtz SM (2012) Chapter 4-Morphology and ccrystalline architecture of polyaryletherketones. In: Kurtz SM (ed) PEEK biomaterials handbook. William Andrew Publishing, Oxford, pp 49-60

[35] Saleem H, Haneef M, Abbasi HY (2018) Synthesis route of reduced graphene oxide via thermal reduction of chemically exfoliated graphene oxide. Mater Chem Phys 204:1-7

[36] Thema FT, Moloto MJ, Dikio ED, Nyangiwe NN, Kotsedi L, Maaza M, Khenfouch M (2013) Synthesis and characterization of graphene thin films by chemical reduction of exfoliated and intercalated graphite oxide. J Chem, 150536.

[37] Wang Y, Beard JD, Evans KE, Ghita O (2016) Unusual crystalline morphology of Poly Aryl Ether Ketones (PAEKs). RSC Adv 6(4):3198-3209

[38] Besra L, Liu M (2007) A review on fundamentals and applications of electrophoretic deposition (EPD). Prog Mater Sci 52(1):1-61

[39] Díez-Pascual AM, Naffakh M, Gómez MA, Marco C, Ellis G, Martínez MT, Ansón A, González-Domínguez JM, Martínez-Rubi Y, Simard B (2009) Development and characterization of PEEK/carbon nanotube composites. Carbon 47(13):3079-3090

[40] Rieger J (2001) The glass transition temperature $\mathrm{Tg}$ of polymers-Comparison of the values from differential thermal analysis (DTA, DSC) and dynamic mechanical measurements (torsion pendulum). Polym Testing 20(2):199-204

[41] Cebe P (1988) Annealing study of poly(etheretherketone). J Mater Sci 23(10):3721-3731. https://doi.org/10.1007/ BF00540520

[42] Cebe P, Hong S-D (1986) Crystallization behaviour of poly(ether-ether-ketone). Polymer 27(8):1183-1192 
[43] Day M, Suprunchuk T, Cooney JD, Wiles DM (1988) Thermal degradation of poly(aryl-ether-ether-ketone) (PEEK): A differential scanning calorimetry study. J Appl Polym Sci 36(5):1097-1106

[44] Jonas A, Legras R (1991) Thermal stability and crystallization of poly(aryl ether ether ketone). Polymer 32(15):2691-2706

[45] Mehmet-Alkan AA, Hay JN (1992) The crystallinity of poly(ether ether ketone). Polymer 33(16):3527-3530

[46] Zhang Z, Zeng H (1993) Effects of thermal treatment on poly(ether ether ketone). Polymer 34(17):3648-3652

[47] Hay JN, Langford JI, Lloyd JR (1989) Variation in unit cell parameters of aromatic polymers with crystallization temperature. Polymer 30(3):489-493

[48] Strankowski M, Korzeniewski P, Strankowska J, Thomas SS (2018), Morphology, mechanical and thermal properties of thermoplastic polyurethane containing reduced graphene oxide and graphene nanoplatelets. Materials 11(1).
[49] Cheng S, Chen X, Hsuan YG, Li CY (2012) Reduced graphene oxide-induced polyethylene crystallization in solution and nanocomposites. Macromolecules 45(2):993-1000

[50] Wypych G (2012) 2-Material composition, structure and morphological features In: Wypych G (ed) Atlas of material damage. Elsevier, Oxford. pp 7-57. https://doi.org/10.1016/ B978-1-895198-48-5.50005-X

[51] Blanton TN, Majumdar D (2012) X-ray diffraction characterization of polymer intercalated graphite oxide. Powder Diffr 27(2):104-107

[52] Ju H-M, Choi S-H, Huh S-H (2010) X-ray diffraction patterns of thermally-reduced graphenes. J Korean Phys Soc 57(61):1649-1652

Publisher's Note Springer Nature remains neutral with regard to jurisdictional claims in published maps and institutional affiliations. 